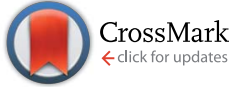

Cite this: RSC Adv., 2017, 7, 9152

Received 21st November 2016 Accepted 12th January 2017

DOI: 10.1039/c6ra27109j

rsc.li/rsc-advances

\section{Investigating microwave deicing efficiency in concrete pavement}

\author{
Song Lu, ${ }^{\star a}$ Jinyu $\mathrm{Xu}^{\text {ab }}$ Erlei Bai, ${ }^{a}$ Junliang Liu ${ }^{a}$ and Xin Luoc
}

Microwave deicing is an intelligent and environmentally friendly method that overcomes the many shortfalls of traditional deicing methods, including mechanical, chemical and thermal techniques. In this paper, a robust method was investigated and the microwave deicing efficiency was defined as the temperature-rise rate of a concrete surface heated to $0{ }^{\circ} \mathrm{C}$. The heating of a concrete surface covered with an ice layer using microwaves from a rectangular waveguide was explored numerically and experimentally. A microwave deicing simulation model was constructed on the basis of finite element theory. Laboratory experiments were then carried out using a self-designed microwave deicing apparatus. The effects of the microwave frequency and pavement material on the microwave deicing efficiency were examined. The results indicate that the microwave efficiency is closely linked with the microwave frequency and pavement material. Compared with the use of a frequency of $2.45 \mathrm{GHz}$, using $5.8 \mathrm{GHz}$ radiation decreased the penetration depth to $45 \%$, while the microwave deicing efficiency increased by more than fivefold. When black iron oxide was added into the concrete mortar at $10 \mathrm{wt} \%$ of the total cement content, the microwave efficiency increased by more than 1.8-fold. Furthermore, the validity of the simulation model based on finite element theory was verified by the consistent results obtained between the simulations and experiments. Moreover, these results could provide theoretical guidance for the future application of microwave deicing.

\section{Introduction}

Winter ice can greatly reduce the friction coefficient of a pavement. On an icy pavement, automobile brake difficulties can cause accidents, while an increase in aircraft taxiing distance can easily cause overshooting. Pavement freezing has become a serious threat to transportation safety. ${ }^{1}$ Therefore, it is very important to study effective methods to remove ice from pavements, and in particular, from important traffic facilities such as highways, airports and roads.

To deice pavements, the traditional methods are mechanical, chemical, or thermal. The mechanical method, which is easy to operate, requires substantial manpower and material resources, and its deicing effect is also not satisfactory, because the vibration and improper use of the machinery can lead to serious damage of the pavement surface. ${ }^{2}$ Moreover, mechanical devices cannot be used under some severe environmental conditions. As for the chemical method, it may be effective in its ability to deice, but the salts required to remove the ice, mainly NaCl-based melting agents, may affect the chemical composition of the concrete structure and pollute the environment. ${ }^{3}$ The thermal

aDepartment of Airfield and Building Engineering, Air Force Engineering University, Xi'an 710038, China.E-mail: lusong647@163.com

${ }^{b}$ College of Mechanics and Civil Architecture, Northwest Polytechnic University, Xi'an 710072, China

${ }^{c}$ Construction Engineering Planning \& Design Institute, Logistic Support Department, Central Military Commission, Beijing 100036, China method involves either an internal heating method or an external heating method. The internal heating method involves a heating element buried within the pavement, and possesses several disadvantages such as large investment, high energy consumption and unsatisfactory removal of thick ice. It can only be used for short segments of roadway, such as bridges. ${ }^{4}$ The external heating method involves the use of high-temperature air produced by an old aircraft engine to melt snow and ice. The exhaust from the engine, at high temperatures of up to 400$500{ }^{\circ} \mathrm{C}$, is usually used as the external heat source. Although this method is efficient, the engine fuel consumption is very high and it causes severe heat damage to airport pavement structures. ${ }^{5}$ Rubber particles are also used for deicing; these are inlaid into pavements and can produce self-stress under automobile tire loads, making pavement deicing easier. ${ }^{6}$ However, rubber particles are not suitable for constructing concrete pavements that require high strength, especially for those in airport runways.

Microwaves, which can rapidly heat dielectric and magnetic materials, are commonly used as a heat source. Ice scarcely absorbs microwaves, while concrete is a type of dielectric material. Accordingly, microwaves can heat concrete surfaces directly through the ice layer and weaken the bonding between the ice and concrete surface. Therefore, microwave heating provides an alternative approach for melting ice on the surface of concrete in an efficient and environmentally friendly way, and has good prospects for application to pavement deicing. The United States put forward research into microwave deicing in the 1980s, but the 
method has not been widely adopted, due to low efficiency. ${ }^{7}$ The natural magnetite in taconite is an outstanding microwave absorber and in order to enhance the microwave absorbing capacity of a pavement, Hopstock used taconite as the aggregate to construct a "microwave road". The microwave radiation was greatly absorbed by the taconite and converted into heat, improving microwave deicing efficiency. ${ }^{8}$ Guan et $a .^{9}{ }^{9}$ used a domestic microwave to heat a frozen road specimen. The ice slowly broke away from the specimen surface under the microwave radiation. However, their study lacked in-depth analysis of the factors contributing to the deicing efficiency. Jiao et al. ${ }^{\mathbf{1 0}}$ applied microwave deicing to an asphalt pavement and analyzed the key factors driving the deicing efficiency; however, water, which shows an excellent ability to absorb microwave radiation, was not taken into account in their simulation model. The water from melting ice has a great influence on the distribution of the temperature field. In addition, a number of patents concerning the design of microwave deicing vehicles have been filed. For example, $\mathrm{Xu}$ et al. ${ }^{\mathbf{1 1}}$ designed a model for a microwave deicing vehicle and applied to patent it, while Witt Highway Maintaining Equipment Company Ltd. in Foshan ${ }^{\mathbf{1 2 , 1 3}}$ devoted much effort to developing a microwave deicing vehicle for pavements and obtained two patents. However, microwave deicing has not been adopted in practice, due to its low efficiency. Therefore, the key to the practical application of microwave deicing in pavement deicing lies in the enhancement of the microwave deicing efficiency.

In this paper, the microwave deicing mechanism and the key factors that contribute to the deicing efficiency were analyzed. The microwave deicing efficiency is mainly affected by the microwave frequency and the pavement material, which were analyzed indepth using simulation methods and experiments. A microwave deicing simulation model was constructed based on finite element theory. In order to verify the validity of the simulation model, a self-designed device was used to conduct the microwave deicing in laboratory experiments.

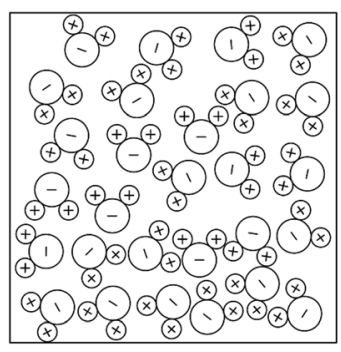

(a) No electric field

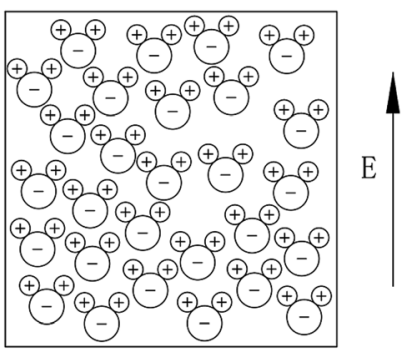

(b) Electric field

Fig. 1 Diagram showing dielectric polarization.

\section{Mechanism analysis}

Microwave deicing refers to the use of microwave radiation, which possesses the ability to rapidly heat dielectric and magnetic materials, to heat concrete. As a truck-mounted microwave generator is driven over an ice-covered road, the microwave radiation should pass through the ice layer, heat the road surface directly, weaken the bonding between the ice and road surface and make it easier to scrape the ice away. The mechanism of microwave deicing can be described as follows. Dielectric and magnetic materials are composed of molecules which can be regarded as electric dipoles or magnetic dipoles. As these materials are not in an electric field, the positive and negative dipoles in the materials are disordered, and can cancel each other out. Therefore, the material as a whole usually does not show electrical properties. When the materials are placed in an electric field, each dipole will deflect along the direction of the field. Based on quantum field theory, this sudden ordering of electric dipoles (generally called polarization) generates a secondary electric field that combines with and strengthens the first field. Moreover, the polarization direction changes as the electric field direction changes, resulting in the rubbing together of molecules. Large heat is produced by the friction generated between different molecules. The faster the electric field direction changes, the more heat will be produced. A diagram of dielectric polarization is shown in Fig. 1.

Based on microwave heating theory, ${ }^{\mathbf{1 4}}$ the microwave power consumed by a material on a per unit volume basis is given simply by:

$$
P=0.556 f E^{2} \varepsilon^{\prime}{ }_{\mathrm{r}} \tan \delta \times 10^{-12}
$$

where $P$ is the power consumed on a per unit volume basis; $f$ is the microwave frequency; $E$ is the electric field intensity; $\varepsilon^{\prime}{ }_{\mathrm{r}}$ is the relative dielectric constant; and $\tan \delta$ is the loss angle constant.

According to eqn (1), the microwave power consumed by a material is related to many factors. It has been generally accepted that different frequencies of microwave radiation have a different effective depth and efficiency. Preliminary studies show that the higher the frequency, the lower the effective depth and the greater the efficiency. ${ }^{15,16}$ Therefore, microwave frequency is a key factor influencing a material's microwave absorbing performance. Moreover, electric field intensity is also related to microwave power. With an increase in the electric field intensity, the polarization increases. Meanwhile, the heat produced by the polarization is greater. In addition, the relative dielectric constant and the loss angle constant are the inherent

Table 1 The characteristic parameters of related substances

\begin{tabular}{|c|c|c|c|c|c|}
\hline Water & 76.7 & 0.157 & 0.63 & 997 & 4179 \\
\hline Concrete & 8 & 0.048 & 1.8 & 2300 & 880 \\
\hline
\end{tabular}


attributes of materials responsible for the microwave-absorbing ability. The larger these parameters are, the stronger the ability is. The characteristic parameters of related substances are listed in Table $1 .^{10}$ The loss angle of ice is close to zero, accounting for the fact that the ice layer, which hardly absorbs microwave radiation, is almost transparent to microwaves. ${ }^{1}$ Therefore, the microwaves can pass through the ice layer and heat the concrete surface directly.

\section{Research methods}

The temperature-rise characteristic of a concrete material under microwave irradiation is very complex, and many factors may influence this parameter. According to the mechanism analysis, microwave frequency and material type are the two prominent factors. In this paper, based on finite element theory, a microwave deicing simulation model was built. In addition, it is practicable to take the temperature-rise rate of a concrete surface heated up to $0{ }^{\circ} \mathrm{C}$ as the index for microwave deicing efficiency. The temperature field distribution in the interior and on the surface of the concrete was analyzed. The influence of the microwave frequency and the material type on the microwave deicing efficiency was analyzed in depth.

\subsection{Simulation model}

The microwave generator of the microwave deicing vehicle is made up of many magnetrons and waveguides. For simplicity, the coupling effects between different microwaves produced by different magnetrons were ignored in this study. The microwave deicing efficiency was studied using a single magnetron and waveguide as an example. Relevant literature reports indicated that the penetration depth for $2.45 \mathrm{GHz}$ microwaves in concrete is about $112 \mathrm{~mm}$ and the penetration depth for $5.8 \mathrm{GHz}$ microwaves in concrete is deeper. ${ }^{14}$ Therefore, the thickness of

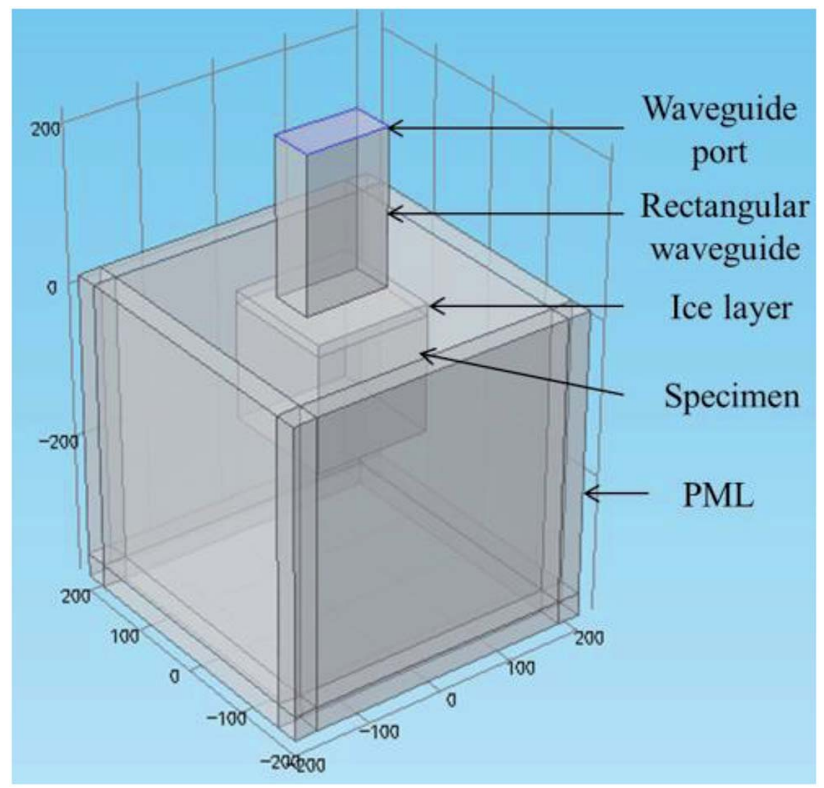

Fig. 2 Microwave deicing simulation model. the specimen was set to $150 \mathrm{~mm}$ and the thickness of the ice layer was set to $15 \mathrm{~mm}$ in the simulation model. Based on finite element theory, the model was built. The mesh graph shown in Fig. 2 indicates that the simulation model is composed of several types of domain, including concrete, ice layer, waveguide and air. The concrete dimensions are $150 \mathrm{~mm} \times 150 \mathrm{~mm}$ $\times 150 \mathrm{~mm}$, the dimensions of the waveguide for $2.45 \mathrm{GHz}$ microwave radiation are $109.2 \mathrm{~mm} \times 54.6 \mathrm{~mm}$ and the dimensions of the waveguide for $5.8 \mathrm{GHz}$ microwave radiation are $40.4 \mathrm{~mm} \times 20.2 \mathrm{~mm}$. A perfect matching layer $(\mathrm{PML})$, which can absorb microwaves from different angles without reflection, was adopted to model the radiation properties in a natural environment. Phase-change heat transfer was used to simulate the ice-to-water process. It can be seen that the water displays excellent microwave absorption, even though the ice layer hardly absorbs microwaves. Thus, the water melting from the ice layer must be seriously considered in the simulation. The origin of the coordinate system is set at the center of the concrete surface, the positive $Z$-axis points to the waveguide, and Path 1 is defined as the line from point $(0,0,-150)$ to point $(0,0,15)$; namely, from the center of the concrete surface to that of the ice layer surface.

\subsection{Laboratory experiments}

Laboratory experiments were conducted on the self-designed microwave deicing apparatus shown in Fig. 3, which is composed of a magnetron, waveguide, adjusting lever for waveguide height, cooling system and circuit system. The height of the waveguide port can be adjusted using the adjusting lever. Two cooling pipes with circulating water were added onto the magnetron to control the internal temperature. The apparatus for generating a frequency of $2.45 \mathrm{GHz}$ is similar to that for generating $5.8 \mathrm{GHz}$, except for the waveguide dimensions, which are the same as those adopted in the simulation

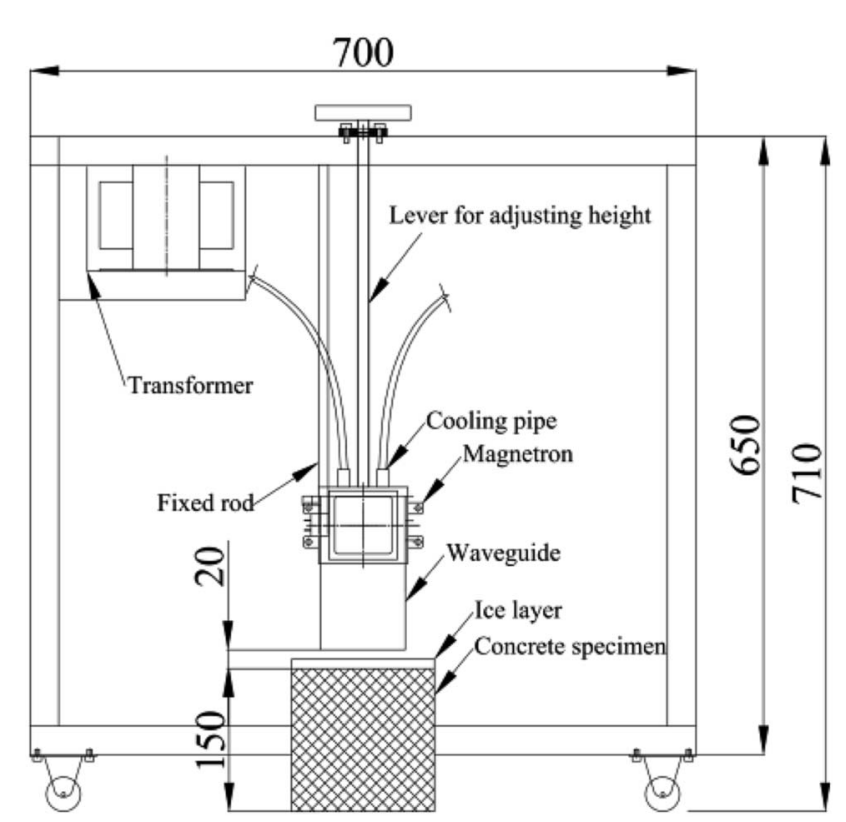

Fig. 3 Microwave deicing experiment apparatus. 
model. In laboratory experiments, the microwave radiation is produced in the magnetron. Then, the microwaves propagate in a direction parallel to the waveguide. When the microwaves reach the waveguide port, they diffuse towards the ice layer and concrete specimen. Then they penetrate the ice layer and heat the concrete surface directly. The surface temperature increases under the microwave irradiation. The concrete specimens of dimensions $150 \mathrm{~mm} \times 150 \mathrm{~mm} \times 150 \mathrm{~mm}$ were covered with a $15 \mathrm{~mm}$-thick ice layer. The thermocouple, recording the temperature change, was positioned at the interface between the concrete surface and the ice layer.

\section{Results and discussion}

\subsection{Microwave frequency}

Microwave frequency is a key factor influencing microwave heating which can affect the electromagnetic parameters of a material and the penetration depth of microwave radiation. A frequency of $2.45 \mathrm{GHz}$ is generally used in industrial microwave heating. However, in contrast to industrial microwave heating, microwave deicing focuses only on the surface temperature change on a pavement. Compared with $2.45 \mathrm{GHz}$ radiation, the heating efficiency of $5.8 \mathrm{GHz}$ radiation is higher and exhibits a smaller penetration depth. Therefore, it is necessary to study the microwave deicing efficiency of $5.8 \mathrm{GHz}$ radiation. This paper reports the deicing efficiency obtained using both simulations and experiments.

4.1.1 Simulation research. In the simulation model, the initial temperature of the air, concrete and ice layer was set to $-10{ }^{\circ} \mathrm{C}$, the height of the waveguide end was set to $20 \mathrm{~mm}$ and the excitation power of the waveguide port was set to $1500 \mathrm{~W}$. Free triangulation and free tetrahedral were adopted for mesh generation. The results demonstrate the relevance of employing a simulation model to microwave deicing.

Fig. 4 shows the highest temperatures achieved at a concrete surface under these two frequencies. The results indicate that when the highest temperature on the concrete surface reaches $0{ }^{\circ} \mathrm{C}$ from the same initial temperature $\left(-10^{\circ} \mathrm{C}\right)$, the microwave

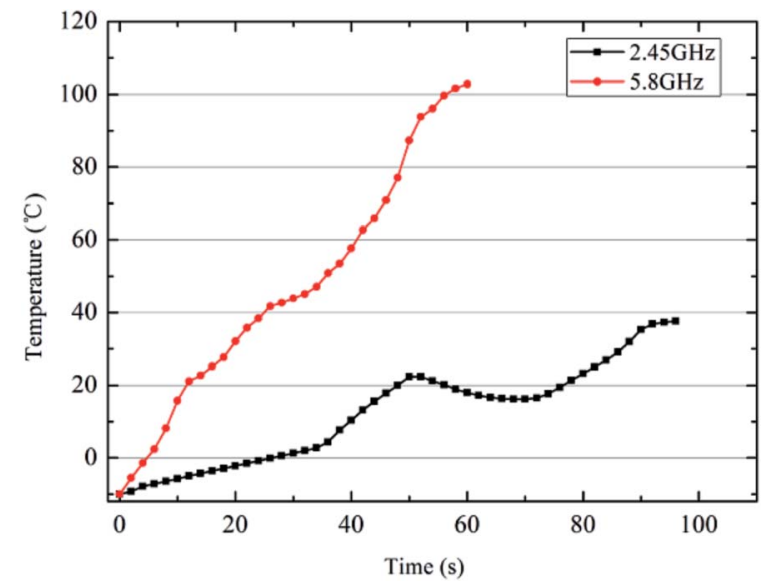

Fig. 4 The maximum surface temperature under frequencies of 2.45 $\mathrm{GHz}$ and $5.8 \mathrm{GHz}$. duration time for $2.45 \mathrm{GHz}$ is $24.5 \mathrm{~s}$ and the temperature-rise rate is $0.41{ }^{\circ} \mathrm{C} \mathrm{s}^{-1}$, whereas for $5.8 \mathrm{GHz}$, the microwave duration time is $4.5 \mathrm{~s}$ and the temperature-rise rate is $2.22{ }^{\circ} \mathrm{C} \mathrm{s}^{-1}$, which is 5.4 times that for $2.45 \mathrm{GHz}$. A possible reason for this observation may be that the polarization direction of the material under the effect of $5.8 \mathrm{GHz}$ radiation changes faster and the friction between the polar molecules is stronger. Consequently, more heat is produced in the material and the surface temperature is higher. In addition, it was observed that the temperature-rise rate increases after the surface temperature reaches $0{ }^{\circ} \mathrm{C}$. This is due to the excellent microwave absorbing ability of water. The polar molecules in water are more active than those in ice. Therefore, more heat is produced in water than in ice under the same microwave radiation. When the ice layer melts into water, the water absorbs more microwave energy and more heat is produced than in ice. Therefore, the temperature-rise rate increases after the surface temperature reaches $0{ }^{\circ} \mathrm{C}$. Another interesting observation is that the temperature-rise rate increases and decreases repeatedly after the ice layer melts into water. The temperature difference between the ice and water is large and leads to heat transfer to the ice layer when the temperature of the water in the ice layer rises to a certain value. The surface temperature-rise rate then becomes slow, resulting in the melting of the ice into water and the absorption of more microwave energy. Then the temperature-rise rate continues to increase and even the surface temperature decreases, which can be clearly seen under the conditions of $2.45 \mathrm{GHz}$ microwave irradiation.

The electric field mode is an important parameter that affects the heat generation rate in microwave heating. Taking Path 1 as an example, this study investigated the distribution of the electric field in concrete. Based on electromagnetic theory, microwave radiation can permeate into a material where the electric field mode decreases to $\mathrm{e}^{-1}$ times that at the material surface. The electric field distributions in concrete under these two frequencies are compared in Fig. 5. It is observed that, for $2.45 \mathrm{GHz}$, the electric field mode is $8.21 \mathrm{kV} \mathrm{m}^{-1}$ on a concrete surface, and the depth is $118 \mathrm{~mm}$ as the field mode decreases to $3.02 \mathrm{kV} \mathrm{m}^{-1}$ ( $\mathrm{e}^{-1}$ times). However, for $5.8 \mathrm{GHz}$, the electric field

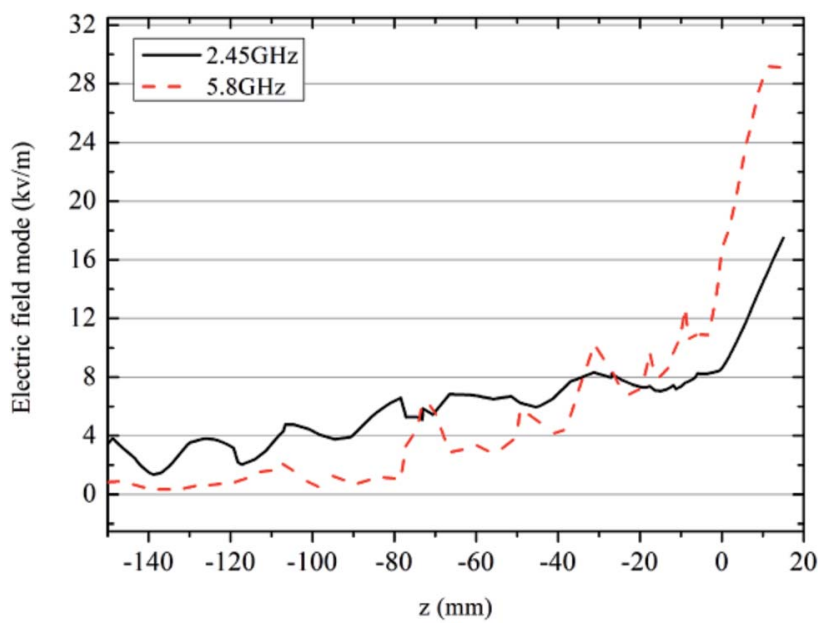

Fig. 5 Electric field distribution in concrete. 


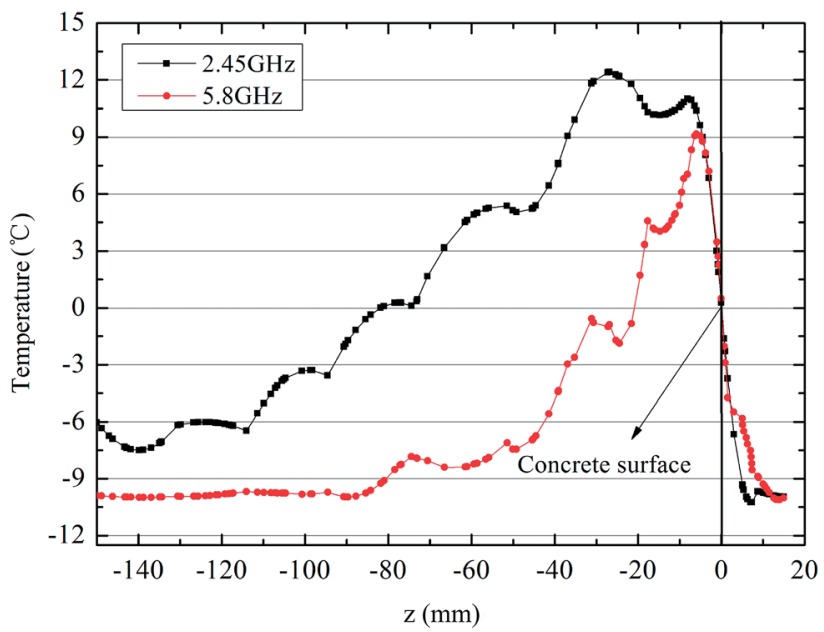

Fig. 6 Temperature field distribution along the vertical direction of concrete.

mode is $12.38 \mathrm{kV} \mathrm{m}^{-1}$ on a concrete surface. As the field mode decreases to $4.56 \mathrm{kV} \mathrm{m}^{-1}$ ( $\mathrm{e}^{-1}$ times), the depth decreases to 53 $\mathrm{mm}$. Therefore, the penetration of $5.8 \mathrm{GHz}$ radiation is just $44.9 \%$ that of $2.45 \mathrm{GHz}$ radiation in microwave deicing, which means that the heat produced by $5.8 \mathrm{GHz}$ microwaves is more concentrated near the concrete surface, indicating that the 5.8 $\mathrm{GHz}$ frequency is more conducive to the application of deicing.

The temperature field distribution inside concrete is demonstrated in Fig. 6, for when the surface temperature reaches $0{ }^{\circ} \mathrm{C}$. The direction of the temperature field distribution is parallel to Path 1. This indicates that the temperature change curves along the direction of Path 1 under these two frequencies are similar. The temperature on the surface of the ice layer is the lowest. Then, the temperature increases with increasing depth until it reaches its peak at about $10 \mathrm{~mm}$ below the concrete surface. After this peak, the temperature decreases with increasing depth. As can be seen from Fig. 6, compared with $2.45 \mathrm{GHz}$, the heat generated by $5.8 \mathrm{GHz}$ radiation is much closer to the concrete surface. The reason for this observation may be that the penetration depth of the $5.8 \mathrm{GHz}$ radiation is smaller than that of the $2.45 \mathrm{GHz}$ radiation. In addition, it also can be seen that the magnitude of the $5.8 \mathrm{GHz}$ radiation is lower than that of the 2.45 $\mathrm{GHz}$ radiation. The main reason for this phenomenon may be that the duration time ( $4.5 \mathrm{~s}$ ) of the $5.8 \mathrm{GHz}$ microwave exposure is much shorter than that $(24.5 \mathrm{~s})$ for the $2.45 \mathrm{GHz}$ microwaves. Thus, the heat produced by $5.8 \mathrm{GHz}$ radiation is less. Above all, it can be concluded that microwaves with a frequency of $5.8 \mathrm{GHz}$ are better for application to pavement deicing.

4.1.2 Experimental research. The concrete specimens were prepared in the mixture ratio of $330 \mathrm{~kg}$ of cement, $136 \mathrm{~kg}$ of water, $4 \mathrm{~kg}$ of superplasticizer, $563 \mathrm{~kg}$ of sand and $1438 \mathrm{~kg}$ of stone per 1 $\mathrm{m}^{3}$. The specimens were then cured in an environmentallycontrolled room at $20{ }^{\circ} \mathrm{C}$ and $95 \%$ relative humidity for 28 days. Then, the ice layer was prepared in a refrigerator at a temperature of $-20{ }^{\circ} \mathrm{C}$. The specimens covered with the ice layer are shown in Fig. 7. A self-designed microwave deicing apparatus was adopted to conduct the microwave deicing

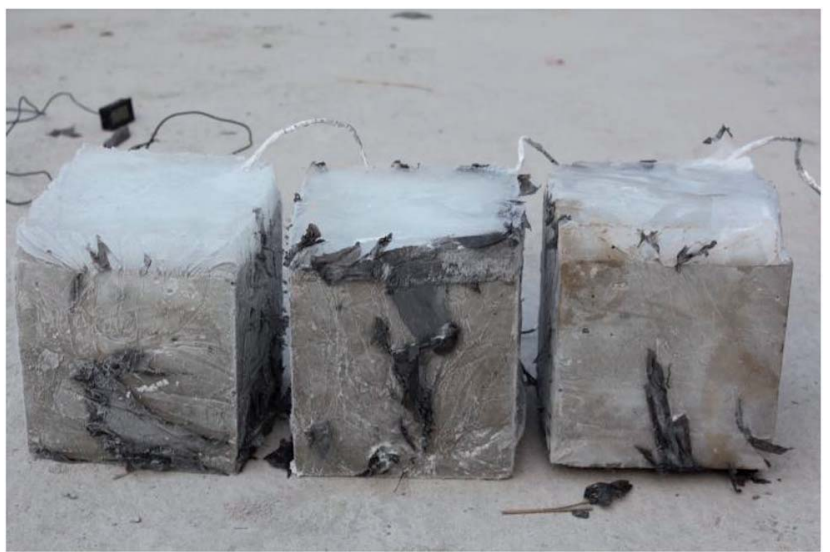

Fig. 7 Specimens covered with ice layer.

experiments. In the experiments, the magnetron power was set to $1500 \mathrm{~W}$ and the waveguide port height was set to $20 \mathrm{~mm}$. The thermocouples, pasted at the interface between the concrete surface and ice layer, were used to record the temperature change on the concrete surface. The surface temperature changes under frequencies of $2.45 \mathrm{GHz}$ and $5.8 \mathrm{GHz}$ were studied.

Fig. 8 displays the ice layer after microwave irradiation. It is observed that there is a large hole in the ice layer. The hole appears to be cone-shaped, which indicates that the ice melted first from the part close to the concrete surface. The adhesion between the ice layer and the concrete surface would then have been reduced and consequently the ice layer could easily have been removed by mechanical means. This phenomenon also indicates that the microwave-absorbing property of the ice layer is weak and that the microwaves could penetrate through the ice layer to heat the concrete directly.

The thermocouples recorded the temperature change at the interface between the concrete surface and the ice layer; the results are shown in Table 2. It can be seen that the initial temperature (namely the environmental temperature) is independent of the

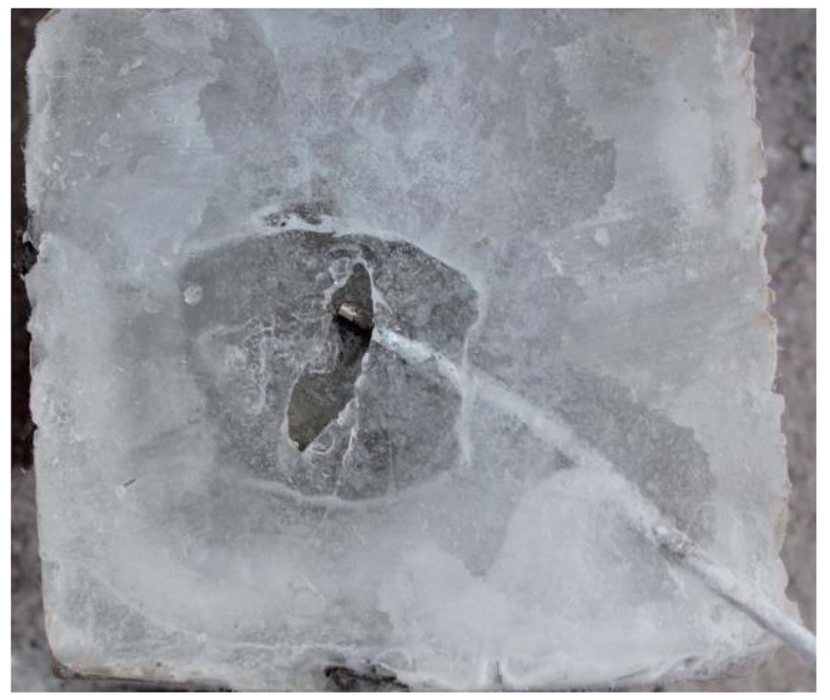

Fig. 8 Ice after microwave irradiation. 
Table 2 Efficiency of concrete under different microwave frequencies

\begin{tabular}{|c|c|c|c|c|c|c|}
\hline \multirow[b]{2}{*}{ Parameters } & \multicolumn{3}{|c|}{$2.45 \mathrm{GHz}$} & \multicolumn{3}{|c|}{$5.80 \mathrm{GHz}$} \\
\hline & 1 & 2 & 3 & 1 & 2 & 3 \\
\hline Heating time/s & 48 & 36 & 30 & 9 & 7 & 6 \\
\hline Temperature-rise rate $/\left({ }^{\circ} \mathrm{C} \mathrm{s}^{-1}\right)$ & 0.33 & 0.36 & 0.34 & 1.59 & 1.83 & 1.73 \\
\hline
\end{tabular}

microwave efficiency, but it affects the deicing time. The lower the initial temperature, the longer the deicing time. The average temperature-rise rate is $0.34{ }^{\circ} \mathrm{C} \mathrm{s}^{-1}$ under $2.45 \mathrm{GHz}$ radiation, whereas for $5.8 \mathrm{GHz}$ radiation, the average temperature-rise rate can reach $1.72{ }^{\circ} \mathrm{C} \mathrm{s}^{-1}$. Therefore, the microwave deicing efficiency of the $5.8 \mathrm{GHz}$ microwaves is 4.99 times of that of the $2.45 \mathrm{GHz}$ microwaves.

The experimental results are very close to the simulation results, indicating the reliability of the simulation model. However, it can be seen that the deicing efficiency obtained in the experiments is slightly lower than that from the simulation research. That is because the electromagnetic parameters are regarded as constant in the simulation model. In reality, these parameters are dependent on the temperature of the material, especially when it is exposed to microwave-frequency radiation. ${ }^{19}$

\subsection{Pavement materials}

The relative dielectric constant and loss tangent are important indicators for the microwave-absorbing properties of materials. Black iron oxide, which is smelted from magnetic ore, is a type of oxide mineral with an equiaxed crystalline structure. This oxide exhibits strong magnetism and has a chemical formula of $\mathrm{Fe}_{3} \mathrm{O}_{4}$. Studies have shown that this type of mineral exhibits perfect performance with respect to microwave-absorption and temperature-rise behavior. ${ }^{18-20}$ In the present work, black iron oxide was doped into cement mortar to improve microwaveabsorbing performance. The dosage of black iron oxide was $10 \mathrm{wt} \%$ of the total cement content. The new electromagnetic parameters, important input parameters for the simulation model, were calculated according to the volume ratio. The new

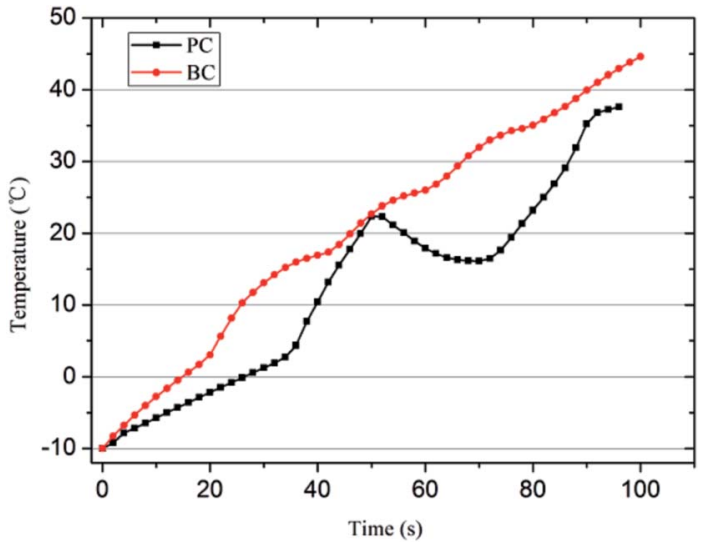

Fig. 9 The maximum surface temperature of $P C$ and $B C$. dielectric constant was 28 and the new loss tangent was 0.075 . Simulations and experiments were conducted on plain concrete (PC) and black iron oxide concrete (BC).

4.2.1 Simulation research. In the simulation model, the initial temperature of the concrete was set to $-10{ }^{\circ} \mathrm{C}$, the frequency was set to $2.45 \mathrm{GHz}$, the power was set to $1500 \mathrm{~W}$ and the waveguide port height was set to $20 \mathrm{~mm}$. The deicing process of PC and BC was simulated based on finite element theory. The highest surface temperatures with time for PC and $\mathrm{BC}$ are demonstrated in Fig. 9. It can be seen that the time taken for the $\mathrm{BC}$ surface temperature to reach $0{ }^{\circ} \mathrm{C}$ is $15 \mathrm{~s}$. The temperature-rise rate is $0.67{ }^{\circ} \mathrm{C} \mathrm{s}^{-1}$, which is 1.87 times that of PC. The black iron oxide, mixed in cement mortar, improves the magnetism of the mixture and transforms the magnetic component into heat. Hence the temperature-rise rate of $\mathrm{BC}$ is higher than that of PC. Another interesting observation is that the temperature-rise rate increases and decreases repeatedly after the ice layer melts into water, which is similar to the trend observed in the study of the microwave frequency.

The temperature field distribution inside the concrete is shown in Fig. 10, for when the highest surface temperature reaches $0{ }^{\circ} \mathrm{C}$. The direction of the temperature field distribution is parallel to Path 1. It can be seen that the general rule of temperature distribution inside these two kinds of concrete is similar, but the highest internal temperature in BC is $7.9^{\circ} \mathrm{C}$, whereas the highest internal temperature in $\mathrm{PC}$ is $12.4^{\circ} \mathrm{C}$. The internal temperature in $\mathrm{PC}$ is higher than that in $\mathrm{BC}$ at the same depth. The reason for this phenomenon is as follows. Black iron oxide increases the electromagnetic parameters of the concrete, so the microwave penetration depth decreases. ${ }^{17}$ Consequently,

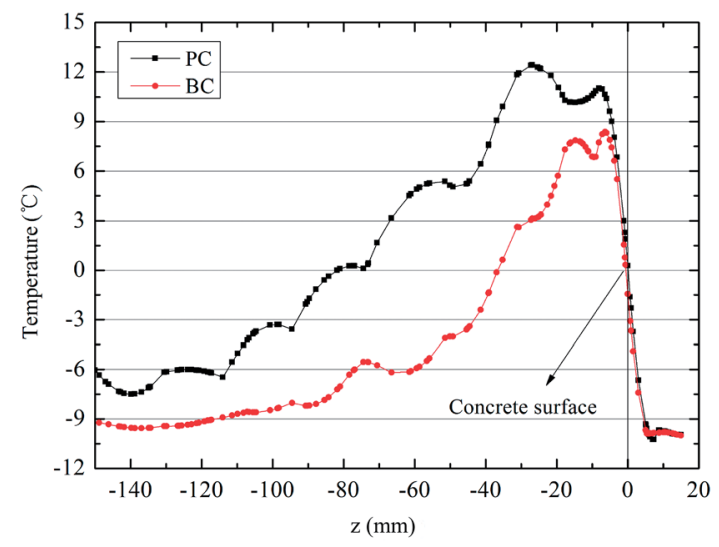

Fig. 10 Temperature field distribution in the vertical direction. 
Table 3 The microwave deicing efficiency of BC

\begin{tabular}{llll}
\hline No. & $\begin{array}{l}\text { Initial temperature } \\
\left({ }^{\circ} \mathrm{C}\right)\end{array}$ & $\begin{array}{l}\text { Heating time } \\
(\mathrm{s})\end{array}$ & $\begin{array}{l}\text { Temperature-rise } \\
\text { rate }\left({ }^{\circ} \mathrm{C} \mathrm{s}^{-1}\right)\end{array}$ \\
\hline 1 & -18.6 & 30 & 0.62 \\
2 & -15.3 & 28 & 0.55 \\
3 & -12.7 & 22 & 0.57 \\
\hline
\end{tabular}

compared with $\mathrm{PC}$, the heat produced by the microwave radiation is much closer to the concrete surface inside $\mathrm{BC}$ and the surface temperature-rise rate of $\mathrm{BC}$ is faster. Therefore, less time is needed to heat the surface temperature to $0{ }^{\circ} \mathrm{C}$ and less heat is produced inside BC. Accordingly, the internal temperature in $\mathrm{PC}$ is higher than that in BC at the same depth.

4.2.2 Experimental research. In order to study the microwave deicing efficiency of concrete with black iron oxide added, the microwave deicing apparatus was used to conduct microwave deicing experiments at the frequency of $2.45 \mathrm{GHz}$ on $\mathrm{BC}$ and PC. The BC specimens were prepared using the same mixture ratio as $\mathrm{PC}$, with $10 \mathrm{wt} \%$ black iron oxide added to the cement content. The preparation of the specimens and the ice layer for BC was the same as those for PC. Table 3 presents the microwave deicing efficiency of $\mathrm{BC}$. It can be seen that the average temperature-rise rate for $\mathrm{BC}$ is $0.58{ }^{\circ} \mathrm{C} \mathrm{s}^{-1}$, which is 1.73 times that for PC. In addition, the experimental results are in general agreement with the simulation results, thus verifying the validity of the simulation model again.

\section{Conclusions}

In this paper, the effects of microwave frequency radiation and pavement material on microwave deicing efficiency were explored numerically and experimentally. The microwave deicing efficiency was defined as the temperature-rise rate of the concrete surface heated up to $0{ }^{\circ} \mathrm{C}$. Based on finite element theory, a microwave deicing simulation model was built and simulations were conducted. Laboratory experiments were carried out using a self-designed microwave deicing apparatus.

The experimental results are in general agreement with the simulation results, verifying the validity of the simulation model. The results show that the microwave efficiency of 5.8 $\mathrm{GHz}$ radiation is about 5 times that of $2.45 \mathrm{GHz}$ radiation. When black iron oxide was added into the concrete at $10 \mathrm{wt} \%$ of the total cement content, the microwave deicing efficiency improved by about 1.8 -fold. In addition, a cone-shape hole formed in the ice layer after microwave irradiation, indicating that the ice layer absorbs little microwave radiation and that the method of microwave deicing is feasible.

Microwave deicing is an intelligent, environmentally friendly method, which overcomes the shortfalls of traditional deicing methods such as mechanical, chemical and thermal methods. In the present study, a microwave deicing simulation model was constructed on the basis of constant parameters in Table 1. However, these parameters change depending upon concrete composition. The effects of the change in these parameters on the microwave deicing efficiency need to be further investigated.
Additionally, in future research more attention should be paid to studying $5.8 \mathrm{GHz}$ microwave radiation and pavement materials with superior microwave-absorbing performance.

\section{Acknowledgements}

The authors would like to acknowledge the Industrial Public Relations Project for Science and Technology Development in Shaanxi Province, China (2014k10-15); the Open Foundation for the State Key Laboratory of Explosion Shock, Disaster Prevention and Reduction (DPMEIKF201406); and Projects of Youth Technology New Star of Shaanxi Province, China (2013KJXX-81).

\section{References}

1 W. Wang, C. Li and G. Tang, et al., Effect of Road Adhesion Coefficient on Tractor-Semitrailer Cornering Braking Stability, Mechanical Engineering and Control Systems. Mechanical Engineering and Control Systems (MECS2015), 2016.

2 Z. D. Hu, S. R. Du, B. C. Shen, et al., Mechanical Property Analysis on Cutting Tool of the Ice and Snow Removing Machine Based on ANSYS, Appl. Mech. Mater., 2015, 779, 74-79.

3 J. S. Seo and S. J. Kwon, Analysis for Chloride Penetration in Concrete under Deicing Agent using Multi Layer Diffusion, Journal of the Korea Contents Association, 2016, 16(4), 114122.

4 K. Huang, T. Xu, G. Li, et al., Heating effects of asphalt pavement during hot in-place recycling using DEM, Constr. Build. Mater., 2016, 115, 62-69.

5 X. W. Tang, Study of Microwave Deicing Efficiency in Pavement, Chang'an University, Xi'an, 2009.

6 D. Niu, S. Han, X. U. Ouming, et al., Pavement performance of rubber asphalt mixture with polyethylene additives, Journal of Jiangsu University, 2016, 4, 479-484.

7 D. M. Hopstock, Microwave-absorbing road construction and repair material, Final Report to NRRI on Idea Evaluation Subcontract, 2003.

8 D. M. Hopstock and L. M. Zanko, Minnesota taconite as a microwave-absorbing road aggregate material for deicing and pothole patching applications, 2005.

9 M. H. Guan, Y. G. Xu, T. J. Lu, et al., Application of microwave heating on removing ice on streets, Journal of Northern Jiao Tong University, 2003, 27(4), 79-83.

10 S. J. Jiao, X. W. Tang, Z. Y. Gao, et al., Study of key technology on microwave deicing efficiency, China J. Highw. Transp., 2008, 21(6), 121-126.

11 Y. G. Xu, X. Li, Z. Ning and C. H. Xu, A kind of microwave deicing vehicle, China, CN02243786. X, 2004-03-10.

12 Midea Group, A way of cleaning up the pavement ice and snow by the magnetron microwave, China, 200710027333, 2007-09-05.

13 Midea Group, A kind of snow sweeping vehicle, China, 200520059734, 2006-08-02.

14 X. W. Tang, S. J. Jiao, Z. Y. Gao, et al., Study of $5.8 \mathrm{GHz}$ magnetron in microwave deicing, J. Electromagn. Waves Appl., 2008, 22(10), 1351-1360. 
15 S. Akbari, A. H. Nour, S. S. Jamari, et al., Demulsification of Water-in-Crude Oil Emulsion via Conventional Heating and Microwave Heating Technology in their Optimum Conditions, Aust. J. Basic Appl. Sci., 2016, 10(4), 66-74.

16 W. X. Sun, L. Z. Wang and P. Z. Zhong, et al., The Study of New Technology of Tempered Glass-Using Microwave Heating Method, International Conference on Advanced Material Science and Engineering, 2016.

17 S. X. Ying, Microwave heating and microwave desiccation, Beijing, National Defence Industry Press, 1976.
18 K. S. Zhou, C. Jing, D. Lianwen, et al., Microwave absorbing properties of Z-type hexaferrite $\mathrm{Sr}_{3}(\mathrm{CuZn})_{x} \mathrm{Co}_{2}(1-x) \mathrm{Fe}_{24} \mathrm{O}_{41}$, J. Cent. South Univ. (Sci. Technol.), 2015, 46(5), 1615-1621.

19 A. Y. Ma, L. B. Zhang, C. Y. Sun, et al., Microwave dielectric properties and temperature increasing characteristics on zinc oxide dust with high content of $\mathrm{Cl}$, J. Cent. South Univ. (Sci. Technol.), 2015, 46(2), 410-415.

20 B. Hu, Z. C. Huang, H. Wang, et al., Temperature rising characteristics of iron and iron oxides in microwave field, J. Cent. South Univ. (Sci. Technol.), 2013, 44(8), 3095-3100. 